\section{Socio-economic status and health care utilization in rural Zimbabwe: findings from Project Accept (HPTN 043)}

\author{
Sebastian Kevany, Oliver Murima, \\ Basant Singh, Daniel Hlubinka, Michal \\ Kulich, Stephen F. Morin, Michael Sweat \\ Institute for Global Health, University of \\ California, San Francisco, CA, USA
}

\section{Abstract}

Zimbabwe's HIV epidemic is amongst the worst in the world, and disproportionately effects poorer rural areas. Access to almost all health services in Zimbabwe includes some form of cost to the client. In recent years, the socio-economic and employment status of many Zimbabweans has suffered a serious decline, creating additional barriers to HIV treatment and care. We aimed to assess the impact of i) socio-economic status (SES) and ii) employment status on the utilization of health services in rural Zimbabwe. Data were collected from a random probability sample household survey conducted in the Mutoko district of north-western Zimbabwe in 2005. We selected variables that described the economic status of the respondent, including: being paid to work, employment status, and SES by assets. Respondents were also asked about where they most often utilized healthcare when they or their family was sick or hurt. Of 2,874 respondents, all forms of healthcare tended to be utilized by those of high or medium-high SES (65\%), including private (65\%), church-based (61\%), traditional (67\%), and other providers (66\%) $(\mathrm{P}=0.009)$. Most respondents of low SES utilized government providers (74\%) $(\mathrm{P}=0.009)$. Seventy-one percent of respondents utilizing health services were employed. Government (71\%), private (72\%), church (71\%), community-based (78\%) and other (64\%) health services tended to be utilized by employed respondents $(\mathrm{P}=0.000)$. Only traditional health services were equally utilized by unemployed respondents (50\%) $(\mathrm{P}=0.000)$. A wide range of health providers are utilized in rural Zimbabwe. Utilization is strongly associated with SES and employment status, particularly for services with user fees, which may act as a barrier to HIV treatment and care access. Efforts to improve access in low-SES, high HIVprevalence settings may benefit from the subsidization of the health care payment system, efforts to improve SES levels, political reform, and the involvement of traditional providers.

\section{Introduction}

\section{Health care in sub-Saharan Africa}

For most people in sub-Saharan Africa, the choice of health care provider is limited. The region bears $24 \%$ of the global burden of disease, but only $3 \%$ of the world's health care workforce. ${ }^{1}$ Shortages of health care professionals, combined with underdeveloped public and private health care systems, mean that the most frequent question most Africans face is one of access to any health care at all, rather than choosing a preferred provider type. While considerable progress has been made in expanding the range of health care services in sub-Saharan Africa in recent years, ${ }^{2}$ as well as in retaining health care professionals in their native countries, ${ }^{3}$ most people in the region, and rural areas in particular, continue to face very limited health care choices.

\section{Health and healthcare in Zimbabwe}

In Zimbabwe, the level and quality of health care delivery has been drastically affected by broader economic and political conditions. Of the 2,086 physicians working in Zimbabwe in $2006^{4}$ only 800 are estimated to remain: that is one physician for every 12,000 people in the country. ${ }^{5}$ Less than $25 \%$ of medical posts in the national health system are filled. Many government or public health services have closed in recent years, ${ }^{6}$ and shortages of drugs and essential medical equipment have brought many hospitals and rural clinics close to ruin. ${ }^{7}$ In this context, the country also faces a number of severe public health threats. Zimbabwe's HIV epidemic is amongst the worst in the world $^{8}$ while the recent cholera outbreak claimed over 3,000 lives. ${ }^{9}$ Tuberculosis and malaria are also widespread, ${ }^{1}$ and the maternal mortality rate is, at 1,100 per 10,000 , the highest in the world. ${ }^{6}$ Life expectancy has fallen from 61 years in the 1990 s to 37 years for men and 34 years for women in $2008 .^{5}$

Nonetheless, the range of health care providers in Zimbabwe continues to compare favorably to other African countries, ${ }^{5}$ at least in part as a result of a legacy of health system development in the 1960s and 1970s, when the Zimbabwean model was hailed as the most efficient and comprehensive in sub-Saharan Africa. ${ }^{5,6}$ The country operates a four-tier health care system, consisting of 56 rural hospitals, 927 public and private health centers providing preventive and curative services, 55 district hospitals, 8 provincial hospitals, 4 general hospitals, and 5 central hospitals located in major cities. ${ }^{10}$ This means that even in rural areas, a range of health care options are often available. ${ }^{11}$ Zimbabweans continue to be able to choose between pharmacies, public and pri-
Correspondence: Sebastian Kevany, Institute for Global Health, University of California, 50 Beale Street, Suite 1300, San Francisco, CA 94105, USA. E-mail: sebastian.kevany@ucsf.edu

Key words: Africa, socio-economic status, HIV/AIDS, access.

Acknowledgments: this research was sponsored by the US National Institute of Mental Health as a cooperative agreement, through contracts U01MH066687 (Johns Hopkins University), U01MH066688 (Medical University of South Carolina), U01MH066701 (University of California, Los Angeles), and U01MH066702 (University of California, San Francisco). In addition, this work was supported by the HIV Prevention Trials Network (HPTN Protocol 043) of the Division of AIDS of the US National Institute of Allergy and Infectious Diseases, and by the Office of AIDS Research of the US National Institutes of Health. Views expressed are those of the authors, and not necessarily those of sponsoring agencies. We thank the communities that helped us conduct this research, and all study participants for their contributions. We also thank study staff and volunteers at all participating institutions for their work and dedication.

Conflict of interest: the authors report no conflicts of interest.

Received for publication: 26 August 2011. Revision received: 26 0ctober 2011.

Accepted for publication: 30 October 2011.

This work is licensed under a Creative Commons Attribution NonCommercial 3.0 License (CC BYNC 3.0).

\section{(C) Copyright S. Kevany et al., 2011}

Licensee PAGEPress, Italy

Journal of Public Health in Africa 2012; 3:e13

doi:10.4081/jphia.2012.e13

vate health clinics, public and private hospitals, church-based clinics and hospitals, private physicians, faith-based or religious healers, traditional healers, and community health workers for their health needs.

Almost all health services in Zimbabwe include some form of cost to the client. The country's national health system is heavily dependent on private expenditure which, makes up $64 \%$ of all health spending and of which $57 \%$ is out-of-pocket. ${ }^{1}$ In a study of costs at a government district hospital, outpatient consultations cost $\$ 24$, antenatal care $\$ 80$, a medical examination $\$ 101$, a general admission $\$ 60$, and a pediatric admission $\$ 30 .{ }^{11}$ Private health care consultations begin at $\$ 200$, and increase to $\$ 500$ per night of inpatient care. ${ }^{6}$ Reports of costs up to $\$ 3,700$ for obstetric care have been reported at the Mbuya Nehanda, the country's largest maternity hos- 
pital. ${ }^{6}$ These costs should be considered in the context of a per capita income of around 500 US $\$ 500 .{ }^{12}$

\section{Socioeconomic status and health care utilization}

In developed countries, the poorest members of society tend to utilize medical services less than others ${ }^{13}$ and this trend is exacerbated in resource-poor settings. The effects of socio-economic status (SES) on health care utilization in developing countries have been extensively documented. In Bangladesh, richer households are nearly twice as likely to seek health care from both qualified and unqualified practitioners. ${ }^{14}$ In Burkina Faso, disadvantaged groups consult health providers half as often, as others. ${ }^{15}$ In Ethiopia, richer households are likely to seek health care both more often and with a greater intensity than poor households. ${ }^{16}$ Common barriers to utilization of health services by persons of low SES include charges and fees, ${ }^{17}$ as well as indirect or opportunity costs of health services use, such as the cost of transport. ${ }^{18}$

The Zimbabwean economy has shrunk by more than $50 \%$ since 1988 , and inflation is currently in excess of $100,000 \%$ per annum. ${ }^{5}$ In this context, the low and declining socio-economic status (SES) of most Zimbabweans, and with it the decline in their purchasing power for health services, means that health care is frequently unaffordable. ${ }^{7}$ Poorer populations are also more likely to be affected by health issues, ${ }^{19}$ and poorer households have been disproportionately affected by HIV/AIDS mortality. ${ }^{16}$ In a study of consultation patterns in urban Zimbabwe, the most commonly cited reasons for not consulting a health care provider were low household income and a lack of money. ${ }^{20}$ The broader economic and political environment in Zimbabwe has also had a devastating impact on disposable income levels. Starting from an already-low average per capita GNP of US $\$ 2,180$ in $2006,{ }^{1}$ hyper-inflation has meant that private savings have often been wiped out and the poor have been plunged into even deeper poverty. ${ }^{21}$ In this context, we aimed to assess the impact of i) SES and ii) employment status on choice and uptake of health care providers in rural Zimbabwe.

\section{Setting}

Mutoko is a rural district with a population of approximately 130,000 people located in the Mashonaland East Province in north-eastern Zimbabwe, some 50 kilometers from the border with Mozambique and approximately 150 kilometers from Harare, Zimbabwe's capital city. Language, ethnicity, and culture are homogeneous, and the local economy is large- ly agricultural, with a high level of subsistence farming and small-scale horticulture. Employment is also provided by the extensive granite and quartz mining industries in the region. Local health services include the Mutoko District Hospital, the Nyadire Mission Hospital, and the Louisa Guidotti Hospital. Traditional healers are also frequently used as a source of health care in the region. Other local health providers include a limited number of private practices and pharmacies, as well as, where and when government support is available, rural public health clinics and community health workers. However, the availability of these latter public services has been significantly curtailed due to the effects of broader economic and political conditions on the ability of the Zimbabwean government to provide public health care, and therefore information on the exact number of these is both limited and unreliable. Mutoko was severely affected by the recent cholera epidemic, ${ }^{22}$ and HIV prevalence in the region is high at approximately $20 \% .^{23}$ Limited antiretroviral services are available in the area. ${ }^{6}$

\section{Materials and Methods}

\section{Data collection, study population and sampling procedures}

Data on SES, employment status and choice of health care provider were collected as part of a larger study which examined the impact of community-based voluntary counseling and testing services on HIV incidence and stigma (Project Accept) which has been described elsewhere. ${ }^{23}$ Forty-eight communities (10 in Tanzania, 8 in Zimbabwe, 16 in South Africa of which 8 in Soweto and 8 in Kwa-Zulu Natal, and 14 in Thailand) were randomized to receive either a community-based HIV voluntary counseling and testing (CBVCT) intervention or standard clinic-based VCT (SVCT). The CBVCT intervention had three major strategies: i) to make VCT more available in community settings; ii) to engage the community through outreach; and iii) to provide post-test support. These strategies were designed to change community norms and reduce the risk of HIV infection among all community members, irrespective of whether they participated directly in the intervention or not.

Baseline assessment methods have been described elsewhere ${ }^{24}$ and involved a twostage probability sample conducted during 2005 and 2006. Briefly, using predefined criteria, trained study staff enumerated the number of members of each household in selected communities. Households were then selected randomly. Each selected household was approached, and an explanation of the study was given to the head of each household. Together with the head of the household, the members of each household were counted. As this was carried out, one person in the 18-32 year old age range was randomly selected. Up to two repeat visits were made until contact was established with the selected household member. Household members were considered eligible to participate in the baseline survey if they were aged 18-32 years, had lived in the community for at least four months in the past year, and if they slept regularly in their household at least 2 nights per week. A total of 5,116 households were visited i) for counting purposes and ii) to solicit participation in the baseline survey. Of these, the members of $95.3 \%$ of these households were counted. 2,871 in-depth interviews were completed based on the willingness and consent of inhabitants to participate in the baseline survey.

\section{Sample and measures}

The study population for this analysis consisted of all eligible males and females between 18 and 32 years of age who responded to questions on i) SES, ii) income and earnings, iii) employment status, and iv) health care utilization.

\section{Statistical analysis}

Using the baseline data set for Zimbabwe, we selected variables that described the economic and employment status of the respondent. These included: i) being paid to work; ii) current employment status; and iii) SES:

i. Being paid to work: respondents were asked if they had been paid to work over the past year by a person, trade, organization, or as self-employed, which included subsistence farming.

ii. Current employment status: respondents were asked what they did for a living (housewife or househusband, employed full time, employed part time, full-time selfemployed, part time self-employed, student, or unemployed). For the purposes of this research, subsistence farming, which is a common income source in the Mutoko region, was classified as full time selfemployed, These categories were then merged as employed (employed full time and employed part time), unemployed (housewives, unemployed, and other employed), self-employed (full time or part time), or students.

iii. SES: this was assessed by three alternative measures in keeping with recommendations for valid and reliable measurement in environments without a single and reliable measure of wealth, ${ }^{25}$ as well as prior studies. ${ }^{15}$ Respondents were asked about their ownership of basic assets (refrigerator, television, stove, cell phone, car or truck in 
working condition, bicycle, motorcycle, livestock, wheelbarrow, scotch cart, radio, access to electricity or tap drinking water in their house); their toilet facilities (no toilet, communal pit latrine, unventilated homestead pit latrine, ventilated homestead pit latrine, shared flush toilet, or homestead flush toilet); and the size and roofing material of their houses (thatch, asbestos, or corrugated tin; presence of a kitchen, granary [hozi] or bedrooms [dhanduru]), and ranked accordingly (Table 1).

For health care utilization, respondents were asked about where they most often utilized medical care or treatment when they or someone in their family was sick or hurt. Response options included traditional healers, pharmacies, public or government health clinics, private health clinics, public or government hospitals, private hospitals, mission or church clinic or hospitals, private physicians, faith or religious healers, and community health workers. In cases of low reported utilization, selected provider types were merged under the following headings: community (traditional healers, religious healers, and community health workers); public (pharmacy, public or governent clinics and hospitals, and mission or church clinics); and private (health clinics, hospitals and physicians).

For each of these variables, univariate analyses were carried out on demographic, SES and health care utilization statistics, SES and health care utilization, income-earning and health care utilization, and employment status and health care utilization. For each of these analyses, P-values were computed using logistical regression, and Pearson's residual values were used to indicate contribution to $\chi^{2}$ statistics. All analyses were conducted using STATA version 9.0 (College Station, Texas, USA).

Table 1. Classification of socio-economic status by homestead, toilet and assets.

\begin{tabular}{lcccc} 
Homestead & Low & Medium-Low & Medium-High & High \\
Toilet & No hozi & No dhanduru & $\begin{array}{c}\text { Dhanduru without } \\
\text { asbestos or tin }\end{array}$ & $\begin{array}{c}\text { One or more } \text { dhanduru } \\
\text { with asbestos or tin } \\
\text { roof }\end{array}$ \\
\hline Assets & No toilet & Shared pit latrine & Pit latrine & Flush toilet \\
\hline & $\begin{array}{c}\text { One or less of: } \\
\text { livestock } \\
\text { wheelbarrow cart }\end{array}$ & $\begin{array}{c}\text { Two or more of: } \\
\text { livestock } \\
\text { wheelbarrow } \\
\text { cart }\end{array}$ & $\begin{array}{c}\text { One or more of: } \\
\text { bicycle } \\
\text { car stove }\end{array}$ & $\begin{array}{c}\text { Two or more of: } \\
\text { motorcycle } \\
\text { car truck } \\
\text { refrigerator } \\
\text { cell phone } \\
\text { electricity } \\
\text { tap water }\end{array}$ \\
& & & &
\end{tabular}

Income earning and health care utilization

Table 5 describes the frequency with which respondents utilized different types of health providers according to income-earning status. Respondents being paid to work tended to utilize public (85.9\%) followed by community health services (7.94\%). Respondents not being paid to work also tended to utilize public health services (82.5\%). In particular, community health care providers tended to be used more frequently by respondents not being paid to work (10.13\%) as compared to respondents being paid to work (7.94\%). Table 6 presents associated $\chi^{2}$ tests and Pearson's residuals of contribution. At the $5 \%$ level, there is a statistically significant association between SES and health care provider for those being paid money to work $(\mathrm{P}=0.043)$.

Table 2. Demographic, socio-economic status and health care utilization characteristics of respondents $(n=2,834)$.

\section{SES and health care provider uti- lization}

Table 3 presents health care provider utilization by SES group. Overall, people of all SES tended to use public health care providers (84.4\%) as opposed to community (8.92\%) or private (6.63\%) providers. Respondents of high SES as measured by homestead (7.66\%), toilet (11.42\%) and assets (11.08\%) were the highest users of private health care services. Conversely, respondents of medium-low SES were the highest users of community health services when measured by homestead (23.07\%), toilet (9.25\%) and assets (11.90\%). Table 4 presents associated $\chi^{2}$ tests and Pearson's residuals of contribution. At the $5 \%$ level, there is a statistically significant association between SES and health care provider for homestead $(\mathrm{P}=0.01)$ and assets $(\mathrm{P}<0.0005)$.

\begin{tabular}{lcc} 
& \multicolumn{2}{c}{ Gender } \\
& Male & Female \\
& n (\%) & n (\%) \\
Age group & & \\
18-22 & $655(53.8)$ & $606(37.5)$ \\
$23-27$ & $338(27.8)$ & $434(26.8)$ \\
28-32 & $224(18.4)$ & $577(35.7)$ \\
Total & $1217(100.0)$ & $1637(100.0)$ \\
Provider & & \\
Community & $98(8.1)$ & $155(9.6)$ \\
Private & $75(6.2)$ & $113(7.0)$ \\
Public & $1044(85.8)$ & $1349(83.4)$ \\
Total & $1217(100.0)$ & $1637(100.0)$ \\
\hline SES (Homestead) & & \\
Low & $35(2.9)$ & $66(4.1)$ \\
Medium low & $7(0.6)$ & $6(0.4)$ \\
Medium high & $345(28.3)$ & $458(28.3)$ \\
High & $830(68.2)$ & $1087(67.2)$ \\
Total & $1217(100.0)$ & $1637(100.0)$ \\
SES (Toilet) & & \\
Low & $403(33.1)$ & $608(37.6)$ \\
Medium low & $51(4.2)$ & $57(3.5)$ \\
Medium high & $754(62.0)$ & $926(57.3)$ \\
High & $9(0.7)$ & $26(1.6)$ \\
Total & $1217(100.0)$ & $1637(100.0)$ \\
SES (Assets) & & \\
High & $159(13.1)$ & $211(13.0)$ \\
Medium high & $667(54.8)$ & $791(48.9)$ \\
Medium low & $156(12.8)$ & $180(11.1)$ \\
Low & $235(19.3)$ & $435(26.9)$ \\
Total & $1217(100.0)$ & $1637(100.0)$ \\
Paid money & & \\
Yes & $739(60.7)$ & $822(50.8)$ \\
No & $478(39.3)$ & $795(49.2)$ \\
Total & $1217(100.0)$ & $1637(100.0)$ \\
\hline Employment & & \\
Employed & $167(13.7)$ & $134(8.3)$ \\
Unemployed & $234(19.2)$ & $487(30.1)$ \\
Self-employed & $744(61.1)$ & $965(59.7)$ \\
Student & & $31(1.9)$ \\
Total & $1637(100.0)$ \\
\hline &
\end{tabular}




\section{Employment status and health care utilization}

Table 5 also describes the frequency with which respondents utilized different types of health providers according to employment status. Respondents of all employment categories tended to use public health care providers (84.43\%). Unemployed respondents reported the highest level of use of community health services (9.7\%), while students (11.65\%) and employed respondents (11.29\%) reported the highest use of private health services. Table 5 also presents associated $\chi^{2}$ tests and Pearson's residuals of contribution. Below the residuals table, there is the P value of the respective test. At the $5 \%$ level, there is a statistically significant association between employment status and health care provider $(\mathrm{P}=0.002)$.

\section{Discussion and conclusions}

\section{Sample characteristics}

The predominant utilization of government health services as primary health care provider suggests a strong dependence on state-supported health care in rural Zimbabwe, and emphasizes the potentially devastating effects of the ongoing breakdown in the Zimbabwean pubic health system in rural areas. Female respondents were significantly more likely to be of low SES than their male counterparts, and male respondents were significantly more likely to be paid to work or to be employed full time. This is in keeping with prior findings on women's limited economic empowerment in Africa, ${ }^{26}$ and may have broader implications for women's health care utilization.

\section{SES and provider utilization}

SES had a strong association with both overall utilization of health services and the utilization of specific health care providers in this study. All forms of health services tended to be utilized by those of high or medium-high SES, independently of how SES was measured. When SES was measured by toilet or assets, there were statistically significant associations between SES and utilization levels. These findings indicate that, with the possible exception of community health services, and with reference to the results presented in Tables 3 and 4, persons of low SES tend to utilize health services less in rural Zimbabwe. This is in keeping with prior findings from resource-poor settings, ${ }^{14,15,17}$ and suggests that the poorest members of society (and often those in greatest need of health care) continue to face a number of barriers to health care utilization. These may include: i) the fees required across all public and private health care providers in Zimbabwe; and ii) the associ-
Table 3. Socio-economic status and health care utilization: bivariate results $(n=2,834)$.

\begin{tabular}{lcrrr} 
& Community & Private & \multicolumn{1}{c}{ Public } & Total \\
Homestead & & & & \\
Low & $9(8.91)$ & $5(4.95)$ & $87(86.13)$ & $101(100.00)$ \\
Medium low & $3(23.07)$ & $0(0.00)$ & $10(76.92)$ & $13(100.00)$ \\
Medium high & $85(10.58)$ & $36(4.48)$ & $682(84.93)$ & $803(100.00)$ \\
High & $156(8.13)$ & $147(7.66)$ & $1614(84.19)$ & $1917(100.00)$ \\
Total & $253(8.92)$ & $188(6.63)$ & $2393(84.43)$ & $2834(100.00)$ \\
Toilet & & & & \\
Low & $90(8.92)$ & $60(5.93)$ & $861(85.16)$ & $1011(100.00)$ \\
Medium low & $10(9.25)$ & $8(7.41)$ & $90(83.33)$ & $108(100.00)$ \\
Medium High & $153(9.10)$ & $116(6.90)$ & $1411(83.98)$ & $1680(100.00)$ \\
High & $0(0.00)$ & $4(11.42)$ & $31(88.57)$ & $35(100.00)$ \\
Total & $253(8.92)$ & $188(6.63)$ & $2393(84.43)$ & $2834(100.00)$ \\
\hline Assets & & & & \\
High & $18(4.86)$ & $41(11.08)$ & $311(84.05)$ & $370(100.00)$ \\
Medium high & $125(8.57)$ & $83(5.69)$ & $1250(85.73)$ & $1458(100.00)$ \\
Medium low & $40(11.90)$ & $25(7.44)$ & $271(80.65)$ & $336(100.00)$ \\
Low & $70(10.44)$ & $39(5.82)$ & $561(83.73)$ & $670(100.00)$ \\
Total & $253(8.92)$ & $188(6.63)$ & $2393(84.43)$ & $2834(100.00)$ \\
\hline
\end{tabular}

Table 4. Socio-economic status and health care provider utilization: $\chi^{2}$ tests and Pearson's residuals of contribution $(n=2,834)$.

\begin{tabular}{lcccc} 
& Community & Private & Public & Total \\
Homestead & & & \\
Low & -0.006 & -0.657 & 0.186 & 0.01 \\
Medium low & 1.707 & -0.929 & -0.295 & \\
Medium high & 1.572 & -2.366 & 0.152 & \\
High & -1.157 & 1.759 & -0.117 & \\
Toilet & & & & \\
Low & -0.027 & -0.863 & 0.251 & 0.466 \\
Medium low & 0.115 & 0.312 & -0.125 & \\
Medium high & 0.247 & 0.431 & -0.201 & \\
High & -1.768 & 1.101 & 0.266 & \\
\hline Assets & & & & \\
High & -2.615 & 3.321 & -0.081 & \\
Medium high & -0.452 & -1.395 & 0.538 & \\
Medium low & 1.827 & 0.574 & -0.755 & \\
Low & 1.317 & -0.817 & -0.199 & \\
\hline
\end{tabular}

Table 5. Employment status, income-earning and health care provider utilization: bivariate results $(\mathrm{n}=\mathbf{2 , 8 3 4})$.

\begin{tabular}{lccrr} 
& Community & Private & \multicolumn{1}{c}{ Public } & Total \\
Paid money & & & & \\
Yes & $124(7.94)$ & $95(6.08)$ & $1342(85.97)$ & $1561(100.00)$ \\
No & $129(10.13)$ & $93(7.31)$ & $1051(82.56)$ & $1273(100.00)$ \\
Total & $253(8.92)$ & $188(6.63)$ & $2393(84.43)$ & $2834(100.00)$ \\
Employment & & & & \\
Employed & $20(6.64)$ & $34(11.29)$ & $247(82.06)$ & $301(100.00)$ \\
Unemployed & $70(9.70)$ & $47(6.51)$ & $604(83.77)$ & $721(100.00)$ \\
Self-employed & $157(9.18)$ & $95(5.55)$ & $1457(82.25)$ & $1709(100.00)$ \\
Student & $6(5.82)$ & $12(11.65)$ & $85(82.52)$ & $103(100.00)$ \\
Total & $253(8.92)$ & $188(6.63)$ & $2393(84.43)$ & $2834(100.00)$ \\
\hline
\end{tabular}

Table 6. Employment status, income-earning and health care provider utilization: $\chi^{2}$ tests and Pearson's residuals of contribution $(n=2,834)$.

\begin{tabular}{lcccc} 
& Community & Private & Public & Total \\
Paid money & & & & \\
Yes & -1.301 & -0.84 & 0.659 & 0.043 \\
No & 1.44 & 0.931 & -0.729 & Total \\
Employment & & & & \\
Employed & -1.326 & 3.14 & -0.449 & 0.002 \\
Unemployed & 0.702 & -0.12 & -0.195 & \\
Self-employed & 0.359 & -1.725 & 0.367 & \\
Student & -1.054 & 1.977 & -0.211 & \\
\hline
\end{tabular}


ated expenditure on transport costs, which are often high enough to make access to health care impossible for many members of society. ${ }^{22}$ Persons of low SES, if utilizing health services at all, almost exclusively utilized government or church-based health services. This indicates a dependence of persons of low SES on a more limited range of health providers than their relatively more affluent counterparts, and indicates that the poorest members of society may be disproportionately affected by associated disruptions to public service delivery.

\section{Income earning and health care uti- lization}

In this study, there was no significant difference in the utilization of health services between respondents who were paid to work and those who were not (Tables 5 and 6). However, differences in the utilization of specific providers between these two groups warrants discussion. In particular, traditional health providers tended to be utilized by respondents who were not paid to work. This is in keeping with prior studies in Africa, in which the most disadvantaged SES groups were found to underutilize modern health care. ${ }^{15}$ Also, community health services tended to be utilized by respondents who were paid to work. In Zimbabwe, traditional healers have the lowest charges and tend to be utilized by the poorest members of society, ${ }^{20}$ and these findings suggest that traditional health services may be more affordable, accessible or otherwise appealing to low- or no-income earners. As the quality and scientific basis of traditional health services in Zimbabwe has been questioned, including documented use of unsterilized razors and administration of medicine through biting, ${ }^{27}$ this trend may lead to poorer persons being exposed to negative health consequences, including increased risk of HIV transmission. This finding also supports the retraining and support of traditional health providers, as proposed by the Zimbabwean Department of Health. ${ }^{28}$ Before the finding that community health services tend to be utilized by those who are paid to work suggests that the design and delivery of community health services, which should in theory be equally accessible to all members of society, may need to be reexamined.

\section{Employment status and health care utilization}

The finding that health care utilization is significantly associated with employment status supports the hypothesis that health services tend to be utilized by the more affluent members of a population. The tendency for government, private, church, community and other health care to be utilized by employed respondents suggests that utilization of many forms of health care may be dependent on work-related benefits such as health insurance. Workplace or employment-related health programs may also be of high importance in increasing utilization of health services.

\section{Limitations}

The data used in this study are cross-sectional, and therefore no assertions can be made about causal pathways. A number of other factors beyond SES, including transport costs and accessibility, have been shown to have a significant influence on the utilization of heath care providers in Africa. ${ }^{29}$ In addition, the age of the study sample, which was limited to 18-32 year olds, may have excluded possible associations between SES and health care utilization in other age groups, particularly in children and the elderly.

\section{Conclusions}

In Zimbabwe, and in Africa in general, there is an increasing need to cater to the health needs of the poorest members of society. However at present, the structure of health systems may deter access to health care by persons of low SES. Advocates of the imposition of health care provider fees in these circumstances should, therefore, be aware that such systems may further limit the ability of the poorest members of society from accessing essential. In countries such as Zimbabwe, as new payment schemes for health systems are proposed and adopted, it should be borne in mind that health services requiring any form of payment on the part of the user will inevitably deter those who may need the most care and treatment. Otherwise, the poorest members of society will continue to have only a limited choice of health care provider. More broadly, the indictment of the effects of the current political, social and economic conditions of the Zimbabwean government on population health is clear. In particular, the inability of the Zimbabwean government to provide even the most basic forms of public health services to its citizens means that those in need are increasingly limited to more expensive private-sector providers, which they can ill-afford.

\section{References}

1. World Health Organization. The World Health Report 2008: Primary Health Care Now More Than Ever. 2008. Available from: http://www.who.int/whr/2008/en/index.htm l

2. International Finance Corporation (2006).
Africa Health Care Report \& IFC Strategy. 2006. Available from: http://www.ifc. org/ifcext/media.nsf/AttachmentsByTitle/S M09_AfricaHealthCare_IssueBrief/\$FILE/ SM09_AfricaHealthCare_IssueBrief.pdf

3. Kumar P. Providing the Providers Remedying Africa's Shortage of Health Care Workers. New Eng J Med 2007;25: 356.

4. World Health Organization. Country Health System Fact Sheet 2006: Zimbabwe. 2006. Available from: www. afro.who.int/home/countries/fact_sheets/z imbabwe.pdf

5. Meldrum A. Zimbabwe's Health-Care System Struggles On. Lancet 2008;371: 1060-1.

6. Lee J (2009). Health Care: Zimbabwe's Luxury. Daily Kos. 2009. Available from: http://www.dailykos.com/story/2009/2/23/12 136/0517/938/700802

7. Wines M. With Health System in Tatters, Zimbabwe Stands Defenseless. New York Times: February 5, 2004.

8. UNAIDS. UNGASS Report on HIV and AIDS. Zimbabwe Country Report. 2008. Available from: http://data.unaids. org/pub/Report/2008/zimbabwe_2008_cou ntry_progress_report_en.pdf

9. BBC News. Zimbabwe Cholera Deaths Top 3,000. 2009. Available from: http://news. bbc.co.uk/2/hi/africa/7855666.stm

10. Encyclopedia of the Nations. The Zimbabwean Health System. 2011. Available from: http://www.nationsencyclopedia.com/Africa/Zimbabwe-HEALTH.html

11. Van der Plaetse B, Hlatiwayo G, Van Eygen L, et al. Costs and Revenue of Health Care in a Rural Zimbabwean District. Health Policy Plann 2005;20:243-51.

12. Nationmaster. Per Capita Incomes Around the World. 2010. Available from: http://www.nationmaster.com/graph/eco_g ro_nat_inc_percap-gross-nationalincome-per-capita

13. Dunlop S, Coyte P, McIsaac W. SocioEconomic Status and the Utilization of Physicians' Services: Results from the Canadian National Population Health Survey. Soc Sci Med 2000;51:123-33.

14. Ahmed S. Exploring Health-Seeking Behaviour of Disadvantaged Populations in Rural Bangladesh. Karolinska University Press, Sweden. 2005. Available from: http:/www.bracresearch.org/publications/thesis_masudbhai.pdf

15. Develay A, Sauerborn R, Diesfeld HJ. Utilization of Health Care in an African Urban Area: Results from a Household Survey in Ouagadougou, Burkina Faso. Soc Sci Med 1996;43:1611-9.

16. Reniers G, Tesfai R. Health services Utilization During Terminal Illness in Addis Ababa, Ethiopia. Health Policy Plann 


\section{Article}

\section{9;4:1-8.}

17. Haddad S, Fournier P. Quality, Cost and Utilization of Health Services in Developing Countries. A Longitudinal Study in Zaire. Soc Sci Med 1995;40:74353.

18. Kroeger A. Anthropological and SocioMedical Health Care Research in Developing Countries. Soc Sci Med 1983; 17:147-61.

19. Harpham T. Health and the Urban Poor. Health Policy Plann 1986;1:5-18.

20. Winston CM, Patel V (1995). Uses of Traditional and Orthodox Health Services in Urban Zimbabwe. Int $\mathrm{J}$ Epidemiol 1995;24:1006-12.

21. BBC. Zimbabwe: Economic Melt-Down. 2000. Available from: http://news. bbc.co.uk/2/hi/africa/978768.stm

22. Medecins Sans Frontieres. Beyond
Cholera: Zimbabwe's Worsening Crisis. Medecins Sans Frontieres Report. 2009. Available from: http:/www.msf.org/source/ countries/africa/zimbabwe/2009/Zimbabw e_Beyond_Cholera_Feb09.pdf

23. Khumalo-Sakutukwa, G., Morin, S.F., Fritz, K., et al. Project Accept (HPTN 043): A Community-Based Intervention to Reduce HIV Incidence in Populations at Risk for HIV in Sub-Saharan Africa and Thailand. JAIDS 2008;49:422-31.

24. Genberg B, et al. HIV Risk Behaviors in Sub-Saharan Africa and Northern Thailand: Baseline Behavioral Data From Project Accept. Journal of Acquired Immune Deficiency Syndromes 2008;49: 309-19.

25. Wojcicki R. Socioeconomic Status as a Risk Factor for HIV Infection in Women in East, Central and Southern Africa: A
Systematic Review. J Biosoc Sci 2005;37:1: 1-36.

26. Dwyer DH, Bruce J. A Home Divided: Women and Income in the Third World. Stanford University Press, Stanford, California, 1988.

27. Simmons D. Assessing the Role of Traditional Healers in Combating HIV/AIDS in Zimbabwe. International Conference on AIDS, July 2000. Abstr.

28. Zimbabwe Health Workforce Observatory. Human Resources for Health Country Profile: Zimbabwe. 2009. Available from: http://www.hrh-observatory.afro.who. int/images/Document_Centre/zimbabwe_hrh_country_profile.pdf

29. Joseph AE, Phillips DR. Accessibility and Utilization: Geographical Perspectives on Health Care Delivery. Sage Publications, New York, 1984. 